\title{
DESTINO DOS ANIMAIS SILVESTRES RECEBIDOS PELO CRIADOURO CONSERVACIONISTA DA UNIVERSIDADE DO VALE DO PARAÍBA
}

\author{
Terezinha Fátima Oliveira ${ }^{1}$ \\ Marcellus P Souza ${ }^{2}$ \\ Maiara Vlahovic ${ }^{3}$ \\ Karla Andressa Ruiz Lopes ${ }^{4}$ \\ Nádia Maria Rodrigues de Campos Velho ${ }^{5}$
}

\begin{abstract}
Resumo: A fauna silvestre vem sendo ameaçada pela constante retirada de animais da natureza. Como uma possibilidade de minimizar o problema foram criados empreendimentos que visam a conservação ex situ da fauna, fazendo a recepção, tratamento e reabilitação. O levantamento dos dados a respeito do recebimento e das reintroduções de animais silvestres foi realizado a partir da movimentação do plantel durante os anos de 2012 a 2014. No período amostrado o recebimento de animais totalizou em 3.270 exemplares, sendo $5,44 \%$ répteis, $83,42 \%$ aves e $11,14 \%$ mamíferos. No mesmo período foram reintroduzidos 2.798 animais, sendo 7,58\% répteis, 82,02\% aves e 10,40\% mamíferos. Levando-se em consideração os dados apresentados observa-se que foram repatriados na natureza $85,56 \%$ dos animais recebidos de 2012 a 2014, indicando um sucesso das reabilitações e na colaboração da conservação das espécies de animais silvestres.
\end{abstract}

Palavras-chave: Fauna silvestre; Conservação, ex situ.

\footnotetext{
1 Universidade do Vale do Paraíba, Brasil. E-mail: terezalessa4@hotmail.com.

2 Universidade do Vale do Paraíba, Brasil. E-mail: mercelluspsouza@gmail.com.

3 Universidade do Vale do Paraíba, Brasil. E-mail: mcrv@outlook.com.

4 Universidade do Vale do Paraíba, Brasil. E-mail: karla@univap.br.

5 Universidade do Vale do Paraíba, Brasil. E-mail: nvelho@univap.br.
} 